\title{
Sex Discrimination Using the Index and Ring Finger Lengths in Ukwuani People of Nigeria
}

Dennis E. O. Eboh

Department of Human Anatomy and Cell Biology, Faculty of Basic Medical Sciences, College of Health Sciences, Delta State University, Abraka, Nigeria

Received: November 1, 2019

Revised: November 14, 2019

Accepted: November 22, 2019

\section{Correspondence to}

Dennis E. O. Eboh

Department of Human Anatomy and Cell Biology, Faculty of Basic Medical Sciences, College of Health Sciences, Delta State University, P.M.B.1, Abraka, Nigeria

Tel: +234-8033872254

E-mail: deeboh@delsu.edu.ng, drebohdennis@gmail.com
The biological profile of a person is crucial in the forensic anthropology casework; and sexual dimorphism of the index and ring fingers makes them a vital tool for sex prediction. This study was undertaken to predict the sex of an individual from the index and ring finger lengths, and index-ring finger length ratio in the Ukwuani of Nigeria. It was a cross-sectional study involving all the indigenous Ukwuani secondary school students and members of staff within Ukwuani local government area that utilized 200 male and 200 female adolescents and 68 male and 83 female adults based on the systematic random sampling technique. The index and ring finger lengths were measured and the index:ring finger ratio calculated. Data were analyzed using SPSS statistics version 23.0. $\mathrm{P}<0.05$ was considered statistically significant. Statistics used were mean, standard deviation, t test, Pearson's correlation, and discriminant function analysis. Males showed statistically longer absolute finger lengths than females. The left index:ring finger ratio in adolescents was significantly greater in females than males, but the others were not. There were significant paired sample correlations in both age groups. There was no significant correlation between age and finger lengths, and ratios. The overall accuracy of the discriminant functions was higher and better for the finger lengths than for the finger ratios that were moderate. This study showed that the index and ring finger lengths can be used as tools to predict the sex of an individual using the discriminant function analysis in a medico-legal situation.

Key Words: Discriminant analysis; Fingers; Forensic anthropology; Nigeria; Sex determination

\section{Introduction}

The biological profile is the distinguishing physical characteristics possessed by an individual which essentially can be determined from the remains. In forensic anthropology, estimating the biological profile of an individual is a critical component in the process of medico-legal investigation of unidentified human remains [1]. The four major biological parameters or elements in the focus of the forensic anthropologist are age, sex, stature and ancestry or ethnicity of the missing individual [2].

In human identification casework, sex determination is crucial, as it reduces the number of possible searches by $50 \%[3,4]$. Traditionally, the biological structures employed for sex determination are the skull and hip bones [5]. However, in situations of murder, assassination and mass disaster, in which dismembered human remains are found, the terminal parts of the body, especially hands and feet are littered around the 
scene $[3,6]$.

The index finger length (IFL), ring finger length (RFL), index finger-ring finger length (IFL:RFL) ratio, have been noted to be sexually dimorphic, and hence ideal for sex determination [3,6-12]. The IFL and RFL are a measure of their relative exposure to estrogen and testosterone respectively before birth [13]. Therefore, it can be extrapolated that the index finger:ring finger ratio is suggestive of the relative exposure of the fingers to prenatal androgen and estrogen, which is controlled by the homeobox genes, particularly the HOX genes $[14,15]$. When the index finger is either equal to or longer than the ring finger, the ratio is relatively large, indicating more exposure to prenatal estrogen, but when the ring finger is longer compared to the index finger, the ratio is small, suggesting greater exposure to testosterone in utero. The former scenario is viewed as a measure of femininity while the latter is masculinity. These genetically determined, sexually dimorphic characteristics of the digit ratio have been said to be same across all populations and does not depend on age and stature [16,17]. Reports have shown that at about 13 and 14 weeks intrauterine life, the development of sexual dimorphism in finger ratios occurs [7,18]; and it remains stable after birth and throughout life [17,19].

Literature search revealed that the few reported studies conducted in Nigeria on the IFL and RFL, and their ratio [20-22] fall short of sex determination using any of the different tools available. In view of ethnicity and population variations among the people of the world due to differences in geographic and environmental locations, there is a need for regional studies on human identification in a situation of dismembered bodies [3]. Nigeria, generally tagged the most populous African country needs to have a population-specific studies in its numerous ethnic nationalities. The Ukwuani people, which communities are oil producing are in the Niger Delta area of Nigeria. This area is known for the spate of killings, murder and kidnapping as a result of agitation for improved conditions of living of the people of the host communities by the oil producing companies [23]. In addition to the aforementioned, the numeric position of this people makes indigenous data that are ethic- specific to be apt. This is so much so, since no study of this sort representing the Ukwuani people is presently recorded in the literature.

This study provided baseline data and in particular discriminant functions or models for sex determination that will be useful to the forensic anthropologists. The purpose of this study was to determine the sex of an individual from the IFL and RFL, and IFL:RFL ratio in Ukwuani people of Nigeria.

\section{Materials and Methods}

\section{Study design, population, and area}

It constitutes a cross-sectional study and the study population was all indigenous Ukwuani secondary school students (13-19 years) and members of staff (20-60 years) within Ukwuani local government area. The Ukwuani ethnic group was chosen because of the numerically large population and as host communities to multi-national oil-producing companies.

\section{Sample and sampling technique}

Five hundred and fifty-one subjects constituted the sample for the study. The systematic random sampling technique was used to select 400 adolescents (200 males and 200 females) and 151 adults (68 males and 83 females) for the study.

\section{Ethical consideration}

Informed consent was obtained from the subjects in accordance with the principles of the use of human subjects in research as enacted in the Declaration of Helsinki as revised [24]. Also, the Institutional Research and Ethics Committee approved the methodology (reference number: REC/FBMS/DELSU/18/32).

\section{Anthropometry}

IFL and RFL were measured as the linear distance in millimeters, from the middle of the proximal crease of the metacarpophalangeal joint to the tip of the respective finger, using the digital Vernier 
caliper (Mitutoyo, Tokyo, Japan) as shown in Fig. 1. Measurements were taken for the right index finger (RIFL), the right ring finger (RRFL), the left index finger (LIFL) and left ring finger (LRFL). The IFL:RFL ratio was calculated as: IFL/RFL.

\section{Selection criteria}

A family pedigree study was conducted and only subjects whose parents up to two generations were Ukwuani participated in the study. The age of the subjects was confirmed from the records in the respective schools. Individuals with hand deformity or who had undergone surgery of the hand were excluded from the study.

\section{Assessment of error of anthropometric measurements}

Twenty volunteers who were not part of the main study sample were selected and measurements of the IFL and RFL were taken on two occasions of 1-week interval. The technical error of measurement (TEM) was calculated using the formula stated below $[25,26]$. $T E M=\sqrt{ }\left(\sum D^{2} \div 2 N\right)$. 'D' stands for the difference between the two measurements; ' $N$ ' the number of subjects measured. "In order to express the error in percentage corresponding to the total average of the variable to

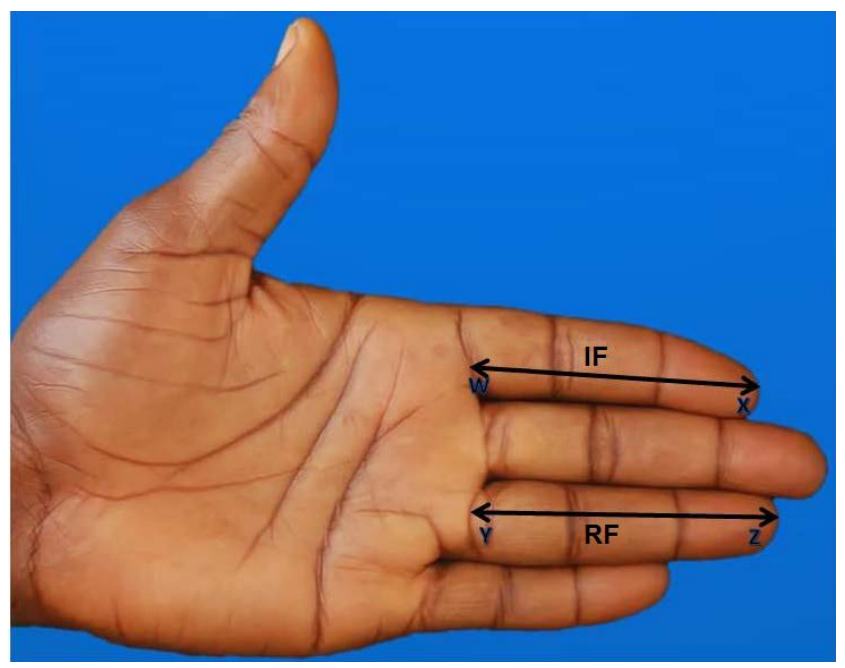

Fig. 1. Measurement landmarks of index and ring fingers. IF, index finger; $R F$, ring finger; $X$, tip of index finger; $Y$, proximal crease of ring finger; $W$, proximal crease of index finger; $Z$, tip of ring finger. be analyzed, the technical error of measurement was transformed into the relative TEM (rTEM), using the following formula" $[25]$ : $r$ TEM $=($ TEM/VAV $) \times 100$. Where TEM is TEM expressed in \% and VAV is variable average value (arithmetic mean of the mean between double measurements).

The absolute TEM was found to be 0.03 for the index finger and 0.04 for the ringer finger, while the rTEM was $0.04 \%$ and $0.06 \%$ for the index and ring finger, respectively. The error values were very minimal and therefore of no effect on the study results.

\section{Data analysis}

Statistical analysis was done with the computer software, IBM SPSS statistics version 23.0. (IBM Corp., Armonk, NY, USA). All P-values $<0.05$ were considered statistically significant. Independent samples t-test was used to determine the mean differences in the IFL and RFL, and IFL:RFL ratio between males and females. Also, paired samples t-test was used to find out mean differences in the IFL and RFL, and IFL:RFL ratio between right and left sides. Pearson's correlation was used to ascertain the level of relationship between paired parameters of IFL, RFL, and IFL:RFL ratio; also the relationship between age and finger parameters. In addition, discriminant function analysis (DFA) was conducted to derive predictive score and function for sex determination; to separate the sexes. IFL and RFL, their ratios and various combinations, were the predictor variables. The predictive model is in this form: $\mathrm{D}=\mathrm{c}+\mathrm{b}_{1} \mathrm{x}_{1}+\mathrm{b}_{2} \mathrm{x}_{2}+\ldots \ldots+\mathrm{b}_{\mathrm{n}} \mathrm{x}_{\mathrm{n}}$; where $\mathrm{D}$ is the predictor or discriminant score, $\mathrm{c}$ is the $\mathrm{Y}$-intercept, $\mathrm{b}$ is the discriminant coefficient, and $\mathrm{x}$ is the predictor and $\mathrm{n}$ is the number of discriminant variables.

\section{Results}

Demographic data showed that 400 (72.6\%) participants were adolescents, 200 (50\%) each for males and females; while 151 (21.4\%) were adults, 68 (45.0\%) males and 83 (55.0\%) females.

Table 1 shows the comparison of the IFL, RFL and their ratios in adolescents and adults. The mean finger lengths in males were statistically longer than in 
Table 1. Comparison of index and ring finger lengths in adolescent and adult

\begin{tabular}{|c|c|c|c|c|c|c|}
\hline Parameter & Data & Range & Mean & SD & $\mathrm{t}$ & P-value \\
\hline \multicolumn{7}{|l|}{ Adolescent } \\
\hline \multirow[t]{3}{*}{ Right index finger (mm) } & Male & $54.13-91.40$ & 71.07 & 6.17 & 4.83 & $<0.001$ \\
\hline & Female & $55.28-81.05$ & 68.43 & 4.66 & & \\
\hline & Combined & $54.13-91.40$ & 69.75 & 5.62 & - & - \\
\hline \multirow[t]{3}{*}{ Left index finger (mm) } & Male & $47.40-89.15$ & 71.32 & 6.34 & 5.18 & $<0.001$ \\
\hline & Female & $55.59-81.54$ & 68.44 & 4.64 & & \\
\hline & Combined & $47.40-89.15$ & 69.88 & 5.73 & - & - \\
\hline \multirow[t]{3}{*}{ Right ring finger (mm) } & Male & $54.68-93.13$ & 75.49 & 6.69 & 5.64 & $<0.001$ \\
\hline & Female & $60.47-85.43$ & 72.22 & 4.76 & & \\
\hline & Combined & $54.68-93.13$ & 73.86 & 6.03 & - & - \\
\hline \multirow[t]{3}{*}{ Left ring finger $(\mathrm{mm})$} & Male & $54.69-92.75$ & 76.12 & 6.67 & 6.43 & $<0.001$ \\
\hline & Female & $58.85-85.38$ & 72.40 & 4.75 & & \\
\hline & Combined & $54.69-92.75$ & 74.26 & 6.07 & - & - \\
\hline \multirow[t]{3}{*}{ Right IFL:RFL } & Male & $0.82-1.09$ & 0.94 & 0.04 & -1.20 & 0.232 \\
\hline & Female & $0.84-1.18$ & 0.95 & 0.04 & & \\
\hline & Combined & $0.82-1.18$ & 0.95 & 0.04 & - & - \\
\hline \multirow[t]{3}{*}{ Left IFL:RFL } & Male & $0.81-1.03$ & 0.94 & 0.04 & -2.15 & 0.032 \\
\hline & Female & $0.84-1.06$ & 0.95 & 0.04 & & \\
\hline & Combined & $0.81-1.06$ & 0.94 & 0.04 & - & - \\
\hline \multicolumn{7}{|l|}{ Adult } \\
\hline \multirow[t]{3}{*}{ Right index finger (mm) } & Male & $60.59-88.05$ & 72.34 & 5.36 & 4.54 & $<0.001$ \\
\hline & Female & $59.19-78.60$ & 68.75 & 4.09 & & \\
\hline & Combined & $59.19-88.05$ & 70.37 & 5.02 & - & - \\
\hline \multirow[t]{3}{*}{ Left index finger $(\mathrm{mm})$} & Male & $60.59-84.19$ & 72.43 & 4.87 & 5.29 & $<0.001$ \\
\hline & Female & $59.55-79.48$ & 68.68 & 3.88 & & \\
\hline & Combined & $59.55-84.19$ & 70.37 & 4.72 & - & - \\
\hline \multirow[t]{3}{*}{ Right ring finger (mm) } & Male & $62.71-91.27$ & 77.00 & 5.07 & 5.74 & $<0.001$ \\
\hline & Female & $61.69-85.62$ & 72.44 & 4.68 & & \\
\hline & Combined & $61.69-91.27$ & 74.49 & 5.35 & - & - \\
\hline \multirow[t]{3}{*}{ Left ring finger (mm) } & Male & $60.43-91.80$ & 77.20 & 5.61 & 5.65 & $<0.001$ \\
\hline & Female & $62.40-83.30$ & 72.49 & 4.64 & & \\
\hline & Combined & $60.43-91.80$ & 74.61 & 5.60 & - & - \\
\hline \multirow[t]{3}{*}{ Right IFL:RFL } & Male & $0.84-1.13$ & 0.94 & 0.05 & -1.27 & 0.207 \\
\hline & Female & $0.81-1.07$ & 0.95 & 0.05 & & \\
\hline & Combined & $0.81-1.13$ & 0.95 & 0.05 & - & - \\
\hline \multirow[t]{3}{*}{ Left IFL:RFL } & Male & $0.87-1.05$ & 0.94 & 0.04 & -1.52 & 0.132 \\
\hline & Female & $0.87-1.03$ & 0.95 & 0.03 & & \\
\hline & Combined & $0.87-1.05$ & 0.94 & 0.04 & - & - \\
\hline
\end{tabular}

SD, standard deviation; IFL, index finger length; RFL, ring finger length. 
females $(P<0.05)$ while no significant difference was recorded in the case of IFL:RFL ratio $(P>0.05)$. Also, it was noted that the ring finger was longer that the index finger.

Table 2 depicts a test of significant mean difference between parameters on the right and left sides. Except for the paired ring fingers in adolescent that had the left mean parameter statistically longer than the right $(P<0.001)$, all the other paired samples were statistically not significant $(\mathrm{P}>0.05)$.

Table 3 showed paired sample correlation of parameters between the right and left sides in both age groups. A strong positive significant correlation ( $r>0.83$, $\mathrm{P}<0.001$ ) was observed in each case, except for the digit ratios that were not strong.

Pearson's correlations between age and IFL and RFL, and IFL:RFL ratios are shown in Table 4. The correlation between age and IFL and RFL, and IFL:RFL ratios, on both sides were weak, positive and not statistically significant $(P>0.05)$.

Discriminant analyses (Wilk's lambda) showed there were significant differences $(P<0.001)$ between discriminating groups for the index finger, ring finger, and their combinations in both adolescent

Table 2. Test of significant mean side differences of parameters

\begin{tabular}{|c|c|c|c|}
\hline Parameter & Mean \pm SD & Difference & $\mathrm{t}$ \\
\hline \multicolumn{4}{|l|}{ Adolescen } \\
\hline Length of right index finger (mm)-Length of left index finger (mm) & $-0.13 \pm 2.15$ & -1.20 & 0.233 \\
\hline Length of right ring finger ( $\mathrm{mm})$-Length of left ring finger ( $\mathrm{mm})$ & $-0.40 \pm 2.26$ & -3.56 & 0.000 \\
\hline Right IFL:RFL-Left IFL:RFL & $0.00 \pm 0.04$ & 2.17 & 0.031 \\
\hline \multicolumn{4}{|l|}{ Adult } \\
\hline Length of right index finger (mm)-Length of left index finger ( $\mathrm{mm})$ & $0.00 \pm 2.74$ & 0.01 & 0.990 \\
\hline Length of right ring finger ( $\mathrm{mm})$-Length of left ring finger $(\mathrm{mm})$ & $-0.12 \pm 2.70$ & -0.54 & 0.591 \\
\hline Right IFL:RFL-Left IFL:RFL & $0.00 \pm 0.05$ & 0.38 & 0.706 \\
\hline
\end{tabular}

$\mathrm{SD}$, standard deviation; IFL, index finger length; RFL, ring finger length.

Table 3. Paired sample correlation between right and left parameters

\begin{tabular}{|c|c|c|}
\hline Parameter & Correlation coefficient $(r)$ & P-value \\
\hline \multicolumn{3}{|l|}{ Adolescen } \\
\hline Length of right index finger $(\mathrm{mm})$ and length of left index finger $(\mathrm{mm})$ & 0.93 & $<0.001$ \\
\hline Length of right ring finger $(\mathrm{mm})$ and length of left ring finger $(\mathrm{mm})$ & 0.93 & $<0.001$ \\
\hline Right IFL:RFL and left IFL:RFL & 0.59 & $<0.001$ \\
\hline \multicolumn{3}{|l|}{ Adult } \\
\hline Length of right index finger $(\mathrm{mm})$ and length of left index finger $(\mathrm{mm})$ & 0.84 & $<0.001$ \\
\hline Length of right ring finger $(\mathrm{mm})$ and length of left ring finger $(\mathrm{mm})$ & 0.88 & $<0.001$ \\
\hline Right IFL:RFL and left IFL:RFL & 0.31 & $<0.001$ \\
\hline
\end{tabular}

$\mathrm{IFL}$, index finger length; RFL, ring finger length.

Table 4. Pearson's correlation analysis between age and finger length and ratios $(n=551)$

\begin{tabular}{llccccc}
\hline & $\begin{array}{c}\text { Length of right index } \\
\text { finger }(\mathrm{mm})\end{array}$ & $\begin{array}{c}\text { Length of left index } \\
\text { finger }(\mathrm{mm})\end{array}$ & $\begin{array}{c}\text { Length of right ring } \\
\text { finger }(\mathrm{mm})\end{array}$ & $\begin{array}{c}\text { Length of left ring } \\
\text { finger }(\mathrm{mm})\end{array}$ & $\begin{array}{c}\text { Right } \\
\text { IFL:RFL }\end{array}$ & $\begin{array}{c}\text { Left } \\
\text { IFL:RFL }\end{array}$ \\
\hline Age & $\begin{array}{l}\text { Pearson correlation } \\
\text { coefficient }(r)\end{array}$ & 0.05 & 0.04 & 0.05 & 0.03 & 0.01 \\
\\
\begin{tabular}{l} 
P-value \\
\hline
\end{tabular}
\end{tabular}

$\mathrm{IFL}$, index finger length; RFL, ring finger length. 
Table 5. Discriminant functions and accuracy for sex prediction from finger lengths

\begin{tabular}{|c|c|c|c|c|c|}
\hline Function & Discriminant function & Male accuracy (\%) & $\begin{array}{c}\text { Female accuracy } \\
(\%)\end{array}$ & $\begin{array}{c}\text { Overall accuracy } \\
(\%)\end{array}$ & Cutting point \\
\hline \multicolumn{6}{|l|}{ Adolescent } \\
\hline RIF & $\mathrm{Q}=-12.761+0.183(\mathrm{RIF})$ & 61.0 & 60.0 & 60.5 & 0.00 \\
\hline LIF & $\mathrm{Q}=-12.58+0.180(\mathrm{LIF})$ & 62.0 & 59.0 & 60.5 & 0.00 \\
\hline RRF & $\mathrm{Q}=-12.719+0.172$ (RRF) & 64.0 & 66.5 & 65.3 & 0.00 \\
\hline LRF & $\mathrm{Q}=-12.831+0.173(\mathrm{LRF})$ & 66.5 & 65.0 & 65.8 & 0.00 \\
\hline $\mathrm{RIF}+\mathrm{RRF}$ & $\mathrm{Q}=-12.827+0.010(\mathrm{RIF})+0.164(\mathrm{RRF})$ & 63.0 & 65.0 & 64.0 & 0.00 \\
\hline $\mathrm{LIF}+\mathrm{LRF}$ & $\mathrm{Q}=-12.500-0.031(\mathrm{LIF})+0.197(\mathrm{LRF})$ & 64.5 & 64.5 & 64.5 & 0.00 \\
\hline $\mathrm{RIF}+\mathrm{RRF}+\mathrm{LIF}+\mathrm{LRF}$ & $\begin{aligned} \mathrm{Q}= & -12.028-0.038(\mathrm{RRF})-0.049(\mathrm{RIF})+ \\
& 0.233(\mathrm{LRF})+0.014(\mathrm{LIF})\end{aligned}$ & 63.0 & 63.5 & 63.3 & 0.00 \\
\hline LIF:LRF & $\mathrm{Q}=-23.368+24.82(\mathrm{~L} 2 \mathrm{D}: \mathrm{L} 4 \mathrm{D})$ & 60.0 & 47 & 53.5 & 0.00 \\
\hline \multicolumn{6}{|l|}{ Adult } \\
\hline RIF & $\mathrm{Q}=-14.960+0.213(\mathrm{RIF})$ & 60.3 & 67.5 & 64.2 & 0.00 \\
\hline LIF & $Q=-16.166+0.230($ LIF $)$ & 67.0 & 63.9 & 65.6 & 0.00 \\
\hline RRF & $\mathrm{Q}=-15.331+0.206(\mathrm{RRF})$ & 67.6 & 68.7 & 68.2 & 0.00 \\
\hline LRF & $Q=-14.620+0.196($ LRF $)$ & 72.1 & 73.5 & 72.8 & 0.00 \\
\hline $\mathrm{RIF}+\mathrm{RRF}$ & $\mathrm{Q}=-15.989+0.043(\mathrm{RIF})+0.174(\mathrm{RRF})$ & 64.7 & 66.3 & 65.6 & 0.00 \\
\hline $\mathrm{LIF}+\mathrm{LRF}$ & $Q=-15.607+0.070($ LIF $)+0.143($ LRF $)$ & 69.1 & 71.1 & 70.2 & 0.00 \\
\hline $\mathrm{RIF}+\mathrm{RRF}+\mathrm{LIF}+\mathrm{LRF}$ & $\begin{aligned} \mathrm{Q}=- & 16.055+0.109(\mathrm{RRF})+0.003(\mathrm{RIF})+ \\
& 0.071(\mathrm{LRF})+0.036(\mathrm{LIF})\end{aligned}$ & 67.6 & 67.5 & 67.5 & 0.00 \\
\hline
\end{tabular}

$\mathrm{Q}$, discriminant score; RIF, right index finger; $\mathrm{LIF}$, left index finger; $R R F$, right ring finger; $L R F$, left ring finger.

and adult age groups. However, for the ratios and their combinations, only in left IFL:RFL (LIFL:LRFL) in adolescents was Wilk's lambda statistically significant $(\mathrm{P}=0.032)$.

Table 5 shows discriminant equations or models for sex discrimination from the various predictor variables (IFL and RFL, and their combinations in both age groups, and left index finger (LIF): left ring finger (LRF) in adolescent. In adolescents, the classification results showed that in right index finger (RIF), LIF, right ring finger (RRF), LRF, RIF+RRF, LIF+LRF, $R I F+R R F+L I F+L R F$, and LIF:LRF, 60.5\%, 60.5\%, 65.3\%, $65.8 \%, 64.0 \%, 64.5 \%, 63.3 \%$, and $53.5 \%$ respectively of cross-validated grouped cases were correctly classified. In the adult age group, RIF, LIF, RRF, LRF, RIF+RRF, $\mathrm{LIF}+\mathrm{LRF}, \mathrm{RIF}+\mathrm{RRF}+\mathrm{LIF}+\mathrm{LRF}$, and LIF:LRF, 64.2\%, 65.6\%, $68.2 \%, 72.8 \%, 65.6 \%, 70.2 \%$, and $67.5 \%$ respectively were correctly classified. Wilk's lambda for all the predictor variables were statistically significant $(P<0.05)$ except the ratios; RIFL:RRFL in adolescents and both RIFL:RRFL and LIFL:LRFL in adults ( $P>0.05)$, which were excluded from the equations based on the standard recommendation [27].

\section{Discussion}

In both adolescent and adult age groups, all the linear finger dimensions on both sides were significantly greater in males compared to females. The fact that females mature earlier, and giving the males two extra years to grow could be the reason for the sex differences observed in the present study. Similar results on dimorphic nature of the IFL and RFL have been reported in previous studies in adults $[7,9,11,21]$ and sub adults $[10,22,28]$.

Concerning the relative dimensions (IFL:RFL ratios) in both age groups, earlier reports posit that IFL:RFL ratios have the tendency to be greater in females than in males [29,30], which has been attributed to the relative exposure of the fingers to prenatal estrogen and testosterone. In the present study, the left hand IFL:RFL ratio in adolescent was significantly greater in females than males which is in tandem with the aforesaid. This is also in line with other previous studies 
[8,10,14,22,29-31]. In contrast, the right IFL:RFL ratio in adolescents and the IFL:RFL ratios on both sides in adults in the present study did not show significant differences between the sexes. In this situation, it appears that there was an overwhelming and a modest prenatal testosterone and estrogen exposure, respectively, that affected the popular inclination of IFL:RFL ratio in favor of the female sex. However, this current result is in line with the results of previous studies [3,7]. In another study on adult Urhobo subjects [20], the left IFL:RFL ratio was significantly greater in females than in males, contrary to the right side that the difference was not significant. Population variation due to genetic and other factors peculiar to these people may be responsible for this outcome.

In adolescent and adults, it was observed that the RFL was greater than the IFL in both sexes. The same observation was reported in an earlier study in an adult population [3,7,9,11,12], and subadult populations $[6,10]$. Similar results were also observed in another study in which the ring finger in males was longer than the index finger [8]. On the other hand, in female subjects, they observed the index finger to be longer [8]. Nevertheless, longer ring finger in both sexes [6] and in males [10], have been reported in adolescents. Population differences due to genetic, environmental, and geographic factors could be responsible for the variation observed among the various studies.

Concerning paired sample comparison, no significant differences between sides in the IFL on both sides in adolescents and the IFL and RFL on both sides in the adult age group. This is similar to the results of a study [8] in both sexes, in which there are no significant side differences in the index and ring finger lengths. Nonetheless, the ring finger length on the left is significantly greater than that on the right in the adolescent age group. On paired samples comparison of relative dimensions on both sides in the adult age group, no significant side differences were observed. The IFL:RFL ratio had also been reported not to be statistically significantly different between the right and left sides in both males and females [8]. However, in the present study, there was significantly greater IFL:RFL ratio on the right compared to the left in the adolescent age group. This variation could be attributed to factors such as genetic, environmental, geographic, that influence anthropometric variables across populations.

The significant positive paired sample correlation between the right and left sides may indicate the consistent anthropometric measurements of parameters. It could also indicate uniformity of growth of parameters on both sides.

The current study showed there was no significant correlation between age and both absolute and relative finger lengths. This may suggest dimensional change from adolescent to adult has negligible or no effect. Concerning the digit ratio, a positive correlation with age [29], or negative relationship with age [17,32] has been reported.

DFA for sex determination showed that in adolescent finger lengths, accuracy of sex determination was higher for the ring fingers than the index fingers. The combination of the right fingers and the left fingers separately as well as a combination of all four fingers could only improve the accuracy levels higher than those of index fingers, but the union did not benefit the ring fingers. For the left IFL:RFL ratio, the overall accuracy of sex determination was moderate (53.5\%), lower than those of the finger lengths. In all, the value of the discriminant function greater than 0.00 was suggestive of a male, otherwise it was female.

In the same vein, the ring finger length in adults has a higher accuracy level of sex determination than the IFLs. The highest was the LRF (72.8\%). Similar to the adolescent, the improvement achieved in the various combinations of finger only benefited the index fingers. Again, a discriminant function value greater than the cutting point is indicative of a male, otherwise it is a female.

Previous studies have determined the sex from the index and ring finger lengths, and their ratios. A prior study that used the DFA reported the overall accuracy of sex prediction in IFL:RFL ratio to be $83.6 \%$; and $85.8 \%$ and $81.3 \%$ of males and females were correctly classified [14]. These values are higher than those recorded in the current study. Aboul-Hagag et al. [11] and Kachan et al. [12] used the sectioning point based on the average of mean IFL:RFL ratio of both sexes, but their results are not comparable to those of current study. Other previous studies $[9,10]$ also applied the 
sectioning point and binary logistic regression analysis, hinging on the receiver operating curve (ROC) and their results are also not comparable to the current study. Another previous study [7] used binary logistic regression analysis and ROC to predict the sex and reported that the ability of the predictors to classify sex is: RRFL (70\%) LIFL (73.7\%), LRFL (73.7\%), and RIFL (75.0\%). Expectedly, the different statistical tools adopted in the various studies will give varied results.

In conclusion, males exhibit significant longer index and ring fingers than those of females. Only the left IFL:RFL ratio in adolescent that is significantly greater in females than males; the others are not dimorphic statistically. There are significant paired sample correlations in both age groups. There is no significant correlation between age and finger lengths, and ratios. The overall accuracies of the discriminant functions are higher and better for the finger lengths than for the finger ratios that are moderate. The models derived from the index and ring finger lengths using the DFA may be capable of predicting the sex of an individual in a medico-legal situation.

ORCID: Dennis E.O. Eboh: https://orcid.org/0000-00032821-4185

\section{Conflicts of Interest}

No potential conflict of interest relevant to this article was reported.

\section{Acknowledgments}

I wish to thank all the respective head of schools for permission to conduct the study. Thanks also go to my research assistants for the data collection.

\section{References}

1. Austin D, King RE. The biological profile of unidentified human remains in a forensic context. Acad Forensic Pathol 2016;6:37090.

2. Christensen AM, Passalacqua NV, Bartelink EJ. Forensic anthropology: current methods and practice. San Diego: Academic Press; 2014. p. 1-18.

3. Sen J, Kanchan T, Ghosh A, et al. Estimation of sex from index and ring finger lengths in an indigenous population of Eastern India. J Clin Diagn Res 2015;9:HC01-5.
4. Macaluso PJ Jr. The efficacy of sternal measurements for sex estimation in South African blacks. Forensic Sci Int 2010;202:111.

5. Basic Z, Anteric I, Vilovic K, et al. Sex determination in skeletal remains from the medieval Eastern Adriatic coast - discriminant function analysis of humeri. Croat Med J 2013;54:272-8.

6. Kanchan T, Krishan K, Sharma A, et al. A study of correlation of hand and foot dimensions for personal identification in mass disasters. Forensic Sci Int 2010;199:112

7. Uzun 0 , Oksuz CE, Zihni NB, et al. Sex estimation from index and ring finger lengths in Turkish population. J Clin Diagn 2019;13: AC01-6.

8. Dey S, Kapoor AK. Digit ratio (2D:4D) - A forensic marker for sexual dimorphism in North Indian population. Egypt J Forensic Sci 2016;6:422-8.

9. Ibrahim MA, Khalifa AM, Hagras AM, et al. Sex determination from hand dimensions and index/ring finger length ratio in North Saudi population: medicolegal view. Egyptian J Forensic Sci 2016;6:435-44.

10. Krishan K, Kanchan T, Asha N, et al. Estimation of sex from index and ring finger in a North Indian population. J. Forensic Leg Med 2013;20:471-9.

11. Aboul-Hagag KE, Mohamed SA, Hilal MA, et al. Determination of sex from hand dimensions and index/ring finger length ratio in upper Egyptians. Egyptian J Forensic Sci 2011;1:80-6.

12. Kanchan T, Kumar GP, Menezes RG. Index and ring finger ratio- $A$ new sex determinant in south Indian population. Forensic Sci Int 2008;181:53.

13. Manning JT, Scutt D, Wilson J, et al. The ratio of 2nd to 4th digit length: a predictor of sperm numbers and levels of testosterone, LH and estrogen. Human Reprod 1998;13:3000-4.

14. Setiya M, Jehan M, Godwin R, et al. Sexual dimorphism of digit ratio (2D:4D) in Madhya Pradesh. Int J Sci Study 2017;4:155-9.

15. Kyriakidis I, Papaioannidou P. Epidemiologic study of the sexually dimorphic second to fourth digit ratio (2D:4D) and other finger ratios in Greek population. Coll Antropol 2008;32:1093-8.

16. Eachus P. Finger length, digit ratio and gender differences in sensation seeking and internet self-efficacy. Issues Inf Sci Inf Technol 2007;4:691-701.

17. Manning JT, Stewart A, Bundred PE, et al. Sex and ethnic differences in the 2 nd to 4 th digit ratio in children. Early Hum Dev 2004;80:161-8.

18. Kanchan T, Rastogi P. Sex determination from hand dimensions of North and South Indians.J Forensic Sci 2009;54:546-50.

19. Li C, Jia M, Ma Y, et al. The relationship between digit ratio and sexual orientation in a Chinese Yunnan Han population. Pers Individ Differ 2016;101:26-9.

20. Ebeye OA. Anthropometric study of the 2D:4D digits ratio in Urhobo people of Southern Nigeria. Int J Forensic Med Invest 2017;3:9-15.

21. Ibegbu AO, Danjuma ZC, Hamman WO, et al. Anthropometric study of the index (2nd) and ring (4th) digits in Ebira ethnic group of Nigeria. Asian J Med Sci 4:79-84.

22. Gabriel SO, Hakeem BF, Ezon-Ebidor E, et al. Second to fourth digit ratio in Nigerian Igbos and Yorubas. Sci Res Essay 
2009;4:1146-8.

23. Nkejiaka C. Emergency of ethnic militia movements in the Niger Delta region: from voice to armed struggle in the new democratic era (1999-till present) [dissertation]. Budapest: Central European University; 2010.

24. World Medical Association. World Medical Association Declaration of Helsinki. Ethical principles for medical research involving human subjects. Bull World Health Org 2001;79:373-4.

25. Arroyo M, Freire M, Ansotegui L, et al. Intraobserver error associated with anthropometric measurements made by dietitians. Nutr Hosp 2010;25:1053-6.

26. Ulijaszek SJ, Lourie JA. Intra- and inter-observer error in anthropometric measurement. In: Ulijaszek SJ, Mascie-Taylor CG, eds. Anthropometry: the individual and the population. Cambridge: Cambridge University Press; 1994. p. 30-55.

27. Landau S, Everitt BS. A handbook of statistical analyses using SPSS [Internet]. Boca Raton: Chapman \& Hall/CRC Press; 2004 [cited 2019 May 20]. Available from: http://www.academia.
dk/BiologiskAntropologi/Epidemiologi/PDF/SPSS_Statistical_ Analyses_using_SPSS.pdf.

28. Krishan K, Kanchan T, Asha N. Estimation of stature from index and ring finger length in a North Indian adolescent population. J Forensic Leg Med 2012;19:285-90.

29. Gillam L, McDonald R, Ebling FJ, et al. Human 2D (index) and 4D (ring) finger lengths and ratios: cross-sectional data on linear growth patterns, sexual dimorphism and lateral asymmetry from 4 to 60 years of age. J Anat 2008;213:325-35.

30. Williams TJ, Pepitone ME, Christensen SE, et al. Finger-length ratios and sexual orientation. Nature 2000;404:455-6.

31. Buck JJ, Williams RM, Hughes IA, et al., In-utero androgen exposure and 2nd to 4th digit length ratio-comparisons between healthy controls and females with classical congenital adrenal hyperplasia. Hum Reprod 2003;18:976-9.

32. Fink B, Manning JT, Neave N, et al. Second to fourth digit ratio and hand skill in Austrian children. Biol Psychol 2004;67:375-84. 